ethical guidelines on epidemiological studies [Internet]. World Health Organization; 2009. [cited 2011 Nov 2]. Available from: http://books. google.com/books?id=R3pkPgAACAAJ

3. Rose S. International ethical guidelines for epidemiological studies. Am J Epidemiol. 2009;170(11):1451-2.

4. Rickham PP.Human experimentation.Code of Ethics of the World Medical Association. Declaration of Helsinki. BMJ. 1964 Jul 18;2(5402):177.

5. World Medical Association. Declaration of Helsinki [Internet].2008 [cited 2011 Nov 2]. Available from: http://www.wma.net/en/30publications/ 10policies/b3/index.html
6. Ioannidis JP. Why most published research findings are false. PLoS Med. 2005 Aug;2(8):e124. Epub 2005 Aug 30.

7. Ioannidis JP. Why most discovered true associations are inflated. Epidemiology. 2008 Sep;19(5):640-8.

8. Malmqvist E, Juth N, Lynöe N, Helgesson G. Early stopping of clinical trials: charting the ethical terrain. Kennedy Inst Ethics J. 2011 Mar;21(1):51-78.

9. Bailey RC, Moses S, Parker CB, Agot K, Maclean I, Krieger JN, Williams CF, Campbell RT, Ndinya-Achola JO. Male circumcision for HIV prevention in young men in Kisumu, Kenya: a randomised controlled trial.Lancet. 2007 Feb 24;369(9562):643-56.

\title{
Some ethical issues here: demands of informed consent and ethical justification for research
}

\section{PRAVESH JUNG G}

Department of Humanities and Social Sciences, IIT-Bombay, Powai, Mumbai, 400076 INDIA e-mail: pgjung@iitb.ac.in

In this comment, I intend to highlight some of the bases of the ethical concerns behind the study in question (1). I argue that these concerns should be viewed not merely with alarm but also with a sense of urgency for a demand for some ethical imperativeness. The study, I argue, either misreads or downplays the role and significance of certain principles which I posit are fundamental to the framework of medical ethics (the justification for considering these principles fundamental demands a separate essay)

The concerns that I raise here are based on two characteristics of the study in question:

First, though such studies are labelled 'observational studies' as opposed to controlled experiments, they are not mere armchair introspective observations of one's thoughts. They are carried out in a social space, where the object being observed is an 'other', rather than the 'self' that is doing the observation. (The researcher-subject dichotomy can be seen as an instance of the self-other dichotomy.)

Second, the legitimacy of such a study is derived from the 'end' or the projected result that the study aims to attain. That is to say that the study is not self-justificatory.

These two characteristics respectively form the basis for two pivotal demands of medical ethics -- informed consent and ethical justification for research. These twin demands constitute the major challenges pertaining to the ethicality of a research. The paper will briefly deal with these twin demands in light of the study in question.

\section{The demand of informed consent}

It is often overlooked that though the term 'informed consent'grammatically operates as a single unit, it is constituted by two terms that signify two distinct, though interrelated, demands. The first constituent, 'informed', sets forth the demand to recognise the possibility of asymmetry of information between the researcher and the participants of the study. The second constituent, 'consent', sets forth the demand to recognise the principle of autonomy.

To accept the possibility of asymmetry of information is to acknowledge the fact that individuals may differ in terms of the scope and extent of information that they possess about the world. The principle of autonomy acknowledges, on the other hand, the view that individuals are ends in themselves, and therefore, have the right to self-determination. To recognise this demand made by the principle of autonomy is to recognise that individuals have the right to choose.

However, the principle of autonomy only assures us that all individuals have the right to choose; it does not ascertain that their autonomy also enables them to understand their choices when they actually confront them. In itself, the principle ascertains the attribution of autonomy to an agent at the formal level alone. Therefore, the demand of informed consent brings into operation the related demand for recognising the possible fact of asymmetry of information. The recognition of this possible fact poses a duty for the researcher to provide the necessary information to enable agents to understand the options that they are to choose from. Thus, it is required that the principle of autonomy be supplemented by acknowledgement of the possibility of asymmetry of information. Without this, the autonomy of an agent may merely remain a formal notion without being translated into an actuality.

Thus the term 'informed consent' posits two distinct though related demands upon the researcher: the duty to recognise the autonomous status of an individual, and the duty to provide the information that would enable agents to understand their choices and consciously exercise their autonomy.

This also provides agents (in this case potential study subjects) the following rights: the right to be treated as autonomous 
agents, and the right to be provided information to enable them to understand their choices and exercise their autonomy consciously.

Here it is important to recognise that the demands of informed consent do not logically entail a duty for the agent making the choice- who in this case is the potential subject of the study -to make an ethical choice, even after the relevant information has been provided. It must also be recognised that any form of coercion or incentive to influence the agent's choice would be a breach of the researcher's duty to recognise the agent's autonomous status and, correspondingly, a breach of the agent's right to be treated as autonomous.

The confusion resulting in non-compliance of the principle of informed consent in the spirit demanded by the principle, apart from actions due to callousness or sheer ignorance on the part of the researcher, lies in the researcher's inability to see informed consent as constituted of these two distinct demands. This is true irrespective of the mode (written or oral) by which informed consent is sought. The confusion worsens due to the mistaken reading of the principle of informed consent to entail a duty for the researcher (the one obtaining the informed consent) to shoulder the moral burden of ensuring that the autonomous agent (the potential subject) makes an ethical choice (Of course this assumes that there can be a determinate ethical choice amongst a range of available choices.)

The principle of informed consent does not, and cannot, pose such a moral demand upon the researcher. Doing so would be in conflict with the demand of recognition of the autonomous status of the agent (the potential subject). By and large, I suspect, researchers -- wrongly -- take this to be the duty entailed by the principle of informed consent, while ignoring the actual dual demands of duties placed on them by this principle.

If one misreads the principle of informed consent to entail a duty to draw out a specific choice, even if this choice is an ethical one, then upholding this duty would not only breach the duty of recognising the autonomous status of the agent, it would, apart from raising questions about the legitimacy of terming it as a 'choice' of the agent, also legitimise the modification of the demand posed by the possible fact of asymmetry of information by legitimising the extent, scope and nature of the information to be provided to potential subjects. That is to say that it would legitimise withholding, and/or overemphasis on certain information since the researcher's duty would be to extract an ethical choice from potential subjects rather than to provide the information necessary to enable them to understand their choices and consciously exercise their autonomy by making a choice, irrespective of the ethicality of the choice made.

The study in question, I suspect, confuses the duties entailed by the principle of informed consent with the (fictitious) duty of ensuring that the agent makes a choice that has been predetermined as the ethical choice by the researcher. The consent taken, in the study in question, was informed, to the extent that it provided the minimum information required to enable the researchers to draw out a predetermined choice from the potential subject, namely, that of consenting to be a part of the study. I assume the researchers thought this was an ethical choice for the potential subjects. Thus in their enthusiasm to uphold a duty that they assumed to be entailed by the principle of informed consent, they actually violated the principle and fell short of fulfilling the actual dual duties imposed upon them by the principle. (This exposition assumes that the researchers had agreed to uphold the principle of informed consent and can be justified by the fact that the researchers took oral informed consents from the subjects. However, the principle of autonomy can be and has been challenged, and subjected to examination through the lens of other principles of biomedical ethics such as beneficence or non-maleficence.)

\section{The demand of ethical justification in research}

By and large, biomedical research cannot be self-justificatory (as opposed to say research in 'pure mathematics', or 'speculative mathematics', that engage with abstract problems as ends in themselves, though it may be appropriated later by applied research). By and large, biomedical research must answer the question: 'Why this study?' The question itself has two distinct, though related, elements: technical and ethical. The recognition that the ethical aspect of the question is as relevant as the technical aspect, if not more, is the basis for the growth of the field of medical ethics.

To recognise that study $\mathrm{x}$ is not self-justificatory is to recognise that its justification resides in something other than the study itself -- ' $y$ ', which is the end that the study projects it would achieve in its completion. Hence, the form of such justification is of the nature of a conditional or hypothetical statement (as opposed to a 'categorical' statement). The justification of ' $x$ ' is conditional on the justification provided by ' $y$ ' for ' $x$ '. The formal structure of these justifications would be: 'If $y$, then $x$ stands justified.'

It is to be noted here that ' $y$ ' cannot then derive its justification from ' $x$ ' (this would be a fallacious, circular justification). Given the necessary independence of ' $y$ ' (the justification for ' $x$ ') from ' $x$ ' (the study), ' $y$ ' can change independently of ' $x$ '. However, given that ' $x$ ' derives its justification from ' $y$ ', any change in ' $y$ ' can have a direct impact upon ' $x$ ' and the justification it derives from ' $y$ '. This is why, I would argue, the demand of ethical justification of research obliges the researcher to follow developments in research that could change an understanding of the projected end.

In the case of the study in question, the end was to understand the relation between cervical dysplasia and cervical cancer; it sought to find out whether the former evolved into the latter and if it did, to develop better therapy to prevent cervical cancer. Thus, when the study was approved by the ethics committee of the research council, the study might arguably have been justified on the basis of this projected end which in itself may be granted a fair review. 
However, as already discussed, the projected end of a study is independent of the study itself. Thus, when mid-way through this study, the north American medical journal published the results of another longitudinal study of cervical cancer concluding that cervical dysplasia was a precursor for cervical cancer, and thus all forms of dysplasia warranted treatment, the projected end of the study under question was achieved. The publication would invalidate the justification of this study, and consequently its ethical justification.

However, one could still have argued for the continuance of the study on other grounds.

One such ground might be that the researchers were ignorant of the study published in the north American medical journal. However, if this were so, it would raise serious concerns regarding their credibility given the nature and potential social impact of their research. It would suggest that they breached their duty to take stock of things regularly, a duty posed by the demand of ethical justification and that they overlooked the fact that a change in that which justifies (the projected end) can have an impact, and a crucial one, upon that which is being justified (the study).

One could also argue that though the researchers were aware of the other study, they were sceptical about the definitiveness of its findings. Such a sceptical stance is legitimate provided the scepticism is justifiable. An unjustified sceptical stance would be hollow and unworthy of critical attention.

The ethical justification for such a sceptical stance can be based upon the principle of non-maleficence. The study's proponents can justify their sceptical stand arguing that the aforementioned principle entails a duty to ensure that they be certain about the other study's conclusions before accepting them to be a definitive understanding of cervical cancer and its relation to cervical dysplasia. They are duty-bound to do this, so as to ensure that no harm was done (principle of nonmaleficence) to women with cervical dysplasia (possible cases of cervical cancer) by virtue of the conclusion that the study would generate.

Though it would be hasty to conclude that no genuine reasons pertaining to the scientific or technical aspect of the published study could have made the researchers sceptical and therefore led them to continue the study, these reasons would have to be brought out and defended.

Acknowledgement: I thank all the reviewers for their comments and suggestions.

\section{Reference}

1. Cash R, Wikler D, Saxena A, Capron A, editors. Casebook on ethical issues in international health research. Geneva: World Health Organisation 2009;124-5.

\section{A Film on Clinical Ethics}

Call for ideas...

Clinical ethics remains at the core of the bioethics movement. It is the ethics practiced by clinicians and those in the medical profession at large. However, ethics is not a set of written-down rules and practitioners often have to use their own judgment and discretion, and take critical decisions for the patient. Clinical ethics concerns run the range between questions of decisionmaking, ensuring privacy and confidentiality, taking consent, and negotiating between doing what is in the best interest of the patient, respecting patient's judgment and autonomy, considering end-of-life issues and more. Yet, the path to making a decision is not always smooth and often remains marked by dilemmas, anxieties, hesitations and also certainties and triumphs.

The Centre for Studies in Ethics and Rights (www.cser.in), a premier bioethics research organisation in India that has been researching the various aspects of clinical ethics, invites creative minds to make a film on any aspect of clinical ethics in an Indian context - a documentary, a montage or a creative mix from footage archives!

Purpose of the film: The film would form part of the syllabus for the medical humanities course for doctors.

The tentative budget for the film will be 2.5 lacs (inclusive of all expenses borne by the director), provided in three installments. We would want the finished film in 90 days from the date of the first installment.

To apply, please send the following:

- A concept note (maximum 500 words) mentioning the duration of your film,

- A break-up of the budget

- Your CV (and the CVs of other personnel who might work with you).

to clinicaletics.cser@gmail.com before January 31, 2012.

For any queries that you might have, mail Deapica at clinicalethics.cser@gmail.com Join us on this exciting journey of translating philosophy into a visual narrative 